\title{
Profile of infection in women with vaginal discharge in North India
}

\author{
Nishi Sood ${ }^{1}$, Shyam Sunder Sud ${ }^{2 *}$ \\ ${ }^{1}$ Department of Obstetrics and Gynecology, Indira Gandhi Medical College, Shimla, Himachal Pradesh, India.
}

${ }^{2}$ Department of Obstetrics and Gynecology, M. M. U, Kumarhati, Solan, Himachal Pradesh, India

Received: 11 August 2018

Accepted: 06 September 2018

\section{*Correspondence:}

Dr. Shyam Sunder Sud,

E-mail: drshyamsud2000@yahoo.co.in

Copyright: $\odot$ the author(s), publisher and licensee Medip Academy. This is an open-access article distributed under the terms of the Creative Commons Attribution Non-Commercial License, which permits unrestricted non-commercial use, distribution, and reproduction in any medium, provided the original work is properly cited.

\begin{abstract}
Background: The objective of the present study was to observe the profile of infection in women with vaginal discharge.

Methods: The present study was conducted between October 2013 and September2014. The respondents were females in reproductive age group (15-45 years) attending Obstetrics and Gynaecology OPD with history of vaginal discharge. After detailed clinical examination of the patient, $\mathrm{pH}$ was determined, and the posterior fornix was swabbed with a cotton tip applicator. Further a Whiff (amine) test done; wet mount was immediately prepared and examined. Another swab was sent for Gram's stain and culture.

Results: A total of 200 women with vaginal discharge were studied, of which 146 were diagnosed with pathogens. The most common form of infection was mixed infection which was diagnosed in 69 patients (34.5\%). As a single pathogen, the next most common infection was Bacterial vaginosis seen in 43 patients (15.5\%) and Trichomonas vaginalis seen in 3 patients $(1.5 \%)$.

Conclusions: The clinical manifestations of vaginits are diverse. By knowing the microbiology of the vaginal flora, we could come to the conclusion of the etiology of vaginitis.
\end{abstract}

Keywords: North India, Profile, Vaginal infections

\section{INTRODUCTION}

Vaginitis is an ancient disease and was described by Hippocrates. Vaginal discharge is one of the most common reason for Gynecological consultation being among the 25 most common reasons for consulting physicians in private office practice in the USA. Not all women with vaginal symptoms will have some type of Vaginitis. Vaginitis is found in more than one-quarter of women attending sexually transmitted disease (STD) clinics. ${ }^{1}$ Normal Vaginal flora (lactobacilli) colonizes the vaginal epithelium and may have role in defence against infection. They maintain the normal Vaginal $\mathrm{pH}$ between 3.8 and 4.4. The quality and quantity of Vaginal discharge may alter in the same woman in cycles and over time; each woman has her own sense of normality and what is acceptable or excessive for her. ${ }^{2}$ Despite the control over the vaginal micro-environment exerted by the lactobacilli, many other microorganisms can be cultivated from the Vaginal samples of healthy women. These organisms do not trigger a pathological state, but when one class of them dominates, the resulting imbalance precludes to vaginosis/ vaginitis. ${ }^{3}$ The $\mathrm{pH}$ of the vagina averages about during reproductive life. ${ }^{4,5}$ The acidity is estrogen dependent, falls after the menopause to neutral or even alkalinity. Common symptoms of these include vaginal discharged, odor, introital itching or irritation with all its physical discomforts and socioeconomic connotations, vaginitis constitutes a medical enigma which deserves concern and attention. 
Discharge of a substance from the vagina can in consistency that is thick or thin, clear, cloudy or colored and odorless or foul smelling. Vaginal discharge that suddenly differs in color, odor or consistency, significantly increases or decreases in amount, may indicate an underlying problem like an infection. ${ }^{4}$ Abnormal vaginal discharge predisposes to significant morbidity in the form of vaginal itching, dysparenunia, emotional irritability, pelvic inflammatory disease, infertility, cuff cellulitis, urethral syndrome, pregnancy loss, preterm labor, premature rupture of membranes and chorioamnionitis, to enumerate a few. ${ }^{4}$

Most common causes of symptomatic vaginal discharge are bacterial vaginosis (33-47\%), followed by candidiasis $(20-40 \%)$ and trichomoniasis $(8-10 \%)$. These three conditions account for $90 \%$ of all etiologies of abnormal vaginal discharge. Multiple infections can also coexist. ${ }^{5}$

The uncommon infectious causes include atrophic vaginitis with secondary bacterial infection, foreign body with secondary infection, desquamative inflammatory vaginitis, streptococcal vaginitis (Group A), ulcerative vaginitis associated with Staphylococcus aureus and idiopathic vulvovaginal ulceration associated with human immunodeficiency virus (HIV). ${ }^{6}$

\section{METHODS}

This was a hospital based longitudinal study conducted between October 2012 and July 2014. The study was done on 200 female patients, who attended the Obstetrics and Gynaecology outpatient's department, with complaints of vaginal discharge. Informed consent was taken from the patients identified to be part of this study.

\section{Inclusion criteria}

- Sexually active women of age between 15 and 45 years presenting with vaginal discharge.

\section{Exclusion criteria}

- Women older than 45 years

- Unmarried women

- Pregnant women

- Postmenopausal women

- Patients who have delivered or aborted six weeks prior

- $\quad$ Patients with vaginal bleeding.

A detailed history was recorded and a thorough genital examination was conducted to look for any abnormalities in the vulva, vagina and cervix. The amount, odor, color and consistency of vaginal discharge were noted. The vaginal $\mathrm{pH}$ was measured directly using $\mathrm{pH}$ indicator strips against the posterior fornix. A bimanual examination was done to look for any Adnexal tenderness.

\section{Clinical investigation}

Two vaginal swabs form the posterior vaginal fornix were collected before bimanual examination for each patient examined during this study. One of swabs was sent for amine test and preparation of wet mounts. The second swab was sent for Gram staining and Culture. This minimized the number of swabs collected from woman

The objective of the above tests was as below:

- Amine test: To identify the presence of fishy odor as an evidence of Bacterial vaginosis.

- Wet mount: To identify the presence of the motile Trichomonas and Clue cells.

- Gram Staining: To Confirm the presence of Clue cells, budding yeast cells and psuedohyphae.

- Culture:

For secondary bacterial infection: Swab was inoculated on Blood Agar and Mac Conkey agar, incubated at $37 \mathrm{C}$ for 18 hours. Plates were read next day for isolation and confirmed by a battery of biochemical reactions.

For Fungus: Swab was inoculated on SDA, incubated at $37 \mathrm{C}$ and observed till 4weeks. Growth was confirmed by germ tube test.

\section{Statistical analysis}

The data collected was tabulated in Microsoft Excel Worksheet and computer- based analysis was performed using the SPSS 22.0 software (SPSS, Chicago, IL, USA). For comparison of means, unpaired t-test and one-way ANOVA were used for two and more than two groups respectively. For comparison of proportions, Chi-square test was used. In cases where any one of cell value was less than five, Fisher's exact test was used.

\section{RESULTS}

The means age of the subjects was 30.92 years (ranging from 20 to 45years with a median of 30years). The difference between the mean age for an infected patient and normal person is statistically significant $(\mathrm{p}=0.048<$ $0.05)$ Majority $(191,95.5 \%)$ of the patients belonged to lower socio- economic class (class II or below) (< Rs.5113 per month). The difference between the mean family income between the infected patients and a normal person is statistically significant $(p=0.030<0.05)$. Majority $(134,67 \%)$ of the cases were poorly educated (Primary and below) and the educational status has a definite influence on collected in present study did not support the hypothesis as p- value was $0.474>0.05$ and was statistically insignificant. The mean duration of vaginal discharge in present study was 14.78 months (ranging from 1 month to 5 years with a median of 3 months). 
The calculated $\mathrm{p}$ - value is $0.010 \quad(<0.05)$ and hence statistically significant. Lower abdominal pain was the most common associated symptom seen in $145(72.5 \%)$ of cases, followed by vulvar itching in $62.5 \%$ dysuria in $50 \%$ foul smelling discharge in $37 \%$.

Of the 200 women who reported discharge, most commonly reported discharge was Homogenous thin discharge in $45.5 \%$ cases which can be associated with Bacterial vaginosis, followed by Thick white in $27 \%$ Curdy white in $19 \%$ and Greenish Yellow in $8.5 \%$. Majority of present study subjects was multiparous $(147,73.5 \%)$. The p-value of 0.007 was statistically significant.

The different causes of vaginal discharge as analyzed after studying the symptoms, signs and investigations revealed that individually Bacterial vaginosis to be the most common pathogen (43cases, 21.5\%) followed by Vulvovaginal Candidiasis (31cases, 15.5\%) and Trichomonas vaginalis ( 3 cases, $1.5 \%$ ). However, when looking at an overall picture, the most common infection was mixed infections which include cases of simultaneous existence of $\mathrm{BV}, \mathrm{VVC}$, or $\mathrm{TV}$ and other secondary infections. A total of 69 cases (34.5\%) were diagnosed with mixed infections.

Amongst the 146 infected patients, 68 Patients (34.0\%) were diagnosed with secondary infections. Most common secondary infection was Staphylococcus aureus diagnosed in 30 patients (15\%), followed by Escherichia Coli in $20(10 \%)$, Klebsiella in $15(7.5 \%)$ and Enterococcus in 2 (1.5\%).

Bacterial vaginosis was identified as an infectious pathogen responsible for vaginal discharge in 87cases. The most common symptom was abdominal pain found in 70 patients $(80.4 \%)$, followed by itching in 63 patients (72.4\%), foul smelling discharge in 52 patients $(59.8 \%)$, homogenous grey white discharge in 45 patients $(51.7 \%)$, dysuria in 44 patients $(50.6 \%)$, thick white discharge in 33 patients $(37.9 \%)$ and 27 patients $(31.0 \%)$ reported congested and oedematous vagina.

Bacterial vaginosis was diagnosed if the patients were positively diagnosed ant 3 of the 4-criterion mentioned above. It was observed that all 87 cases $(100 \%)$ had $\mathrm{pH}>$ 4.5 , followed by 71 cases $(81.6 \%)$ were found to have clue cells in the wet mount and 45 cases $(51.7 \%)$ complained of homogenous grey white discharge.Majority of patients with candidiasis presented with vulvar itching which was observed in 48 patients $(85.7 \%)$ followed by 43 patients $(76.8 \%)$ who complained of abdominal pain. 38 patients $(67.8 \%)$ who were diagnosed with Candidiasis had curdy white discharge and dysuria. Per speculum examination revealed congested and oedematous vagina in 35 patients $(62.5 \%)$. In 16 patients $(28.6 \%)$ the discharge was homogenous grey white in characteristic and 14 patients $(25.0 \%)$ had discharge with a foul odor. Candidiasis was diagnosed by either Wet mount, Gram Stain on Culture. 56 patients $(100 \%)$ were tested +ve in the culture, followed by 47 patients $(83.9 \%)$ whose sample revealed budding yeast cells with pseudohyphae in the Gram Stain and 34 patients $(60.7 \%)$ sample contained budding yeast cells in the wet mount. Majority of the patients $(19,90.5 \%)$ diagnosed with Trichomonas vaginalis had dysuria and on examination revealed congested and oedematous vagina. The discharge was Greenish Yellow in $17(80.9 \%)$, foul smelling in 12 patients $(57.1 \%), 18$ patients $(85.7 \%)$ had Vulvar itching and only 13 patients $(61.9 \%)$ had associated abdominal pain.

\section{DISCUSSION}

Vaginitis is a common medical problem in women that is associated with substantial discomfort, significant morbidity and hence frequent medical visits. These infections if not treated or ignored could debilitate the patients and could become a source of infection for the neonate especially in case of women belonging to the childbearing age. ${ }^{7,8}$

\section{Table 1: Prevalence of mixed infection in different studies.}

\begin{tabular}{|c|c|c|}
\hline Study group & Year & Mixed infections \\
\hline Sivaranjini et $\mathrm{al}^{6}$ & 2013 & 5.5 \\
\hline Zimba et al ${ }^{8}$ & 2011 & 11.0 \\
\hline Sobel al ${ }^{9}$ & 2013 & $20.0-30.0$ \\
\hline Thulkar et al ${ }^{11}$ & 2010 & 36.8 \\
\hline Present Study & 2014 & 34.5 \\
\hline
\end{tabular}

Although a common condition identifying the cause of vaginitis remains a challenging task. The clinical presentations of various vaginal conditions are not specific enough to permit establishing the etiologic diagnosis. So, we designed this stud to profile the infections in women with vaginal discharge and understand the common causes of vaginitis.

Among the 200 women who participated in this study, at the Outpatient department of Department of Obstetrics and Gynecology, MMU, with the complaints of vaginal discharge, a total of $146(73 \%)$ women were found infected while the remaining $54(27 \%)$ women were having physiological vaginal discharge. This correlates to Zimba et al. who reported no definite diagnosis in $22 \%$ cases. ${ }^{8}$ Amongst the 146 infected women, it was established that endogenous infections were relatively common. The most commonly infections were mixed infections as observed in 69 patients (34.5\%). This correlates to Sobel et al. who reported that although data remain sparse, mixed vaginitis occurs rarely $(<5 \%)$. By contrast, pathogen mixed infections occur frequently in women with vaginitis. ${ }^{9}$ Approximately $20 \%$ - 30\% of women with Bacterial vaginosis are co- infected with Candida- Coexistence of Bacterial vaginosis and Trichomonas vaginalis is even more common; with co infection rates of $60 \%-80 \% .^{10}$ 
Table 2: Prevalence of BV, VVC and TV in different studies.

\begin{tabular}{|c|c|c|c|c|}
\hline Study Group & Year & Bacterial vaginosis & Candidiasis & Trichomonas vaginalis \\
\hline Vishwanath et al ${ }^{12}$ & 2000 & $26.0 \%$ & - & $10.0 \%$ \\
\hline Bhalla et $\mathrm{al}^{13}$ & 2007 & $32.8 \%$ & $16.9 \%$ & $2.8 \%$ \\
\hline Patel et al ${ }^{14}$ & 2006 & $17.8 \%$ & $8.5 \%$ & - \\
\hline Dan et $\mathrm{al}^{15}$ & 2003 & $23.5 \%$ & $35.5 \%$ & $8.1 \%$ \\
\hline Puri et $\mathrm{al}^{16}$ & 2003 & $45.0 \%$ & $31.0 \%$ & $2.0 \%$ \\
\hline Fonck et al ${ }^{17}$ & 2000 & $9.0 \%$ & $50.0 \%$ & $23.0 \%$ \\
\hline Zaki et al ${ }^{18}$ & 2010 & $39.1 \%$ & $1.0 \%$ & $30.0 \%$ \\
\hline Present study & 2014 & $21.5 \%$ & $15.5 \%$ & $1.5 \%$ \\
\hline
\end{tabular}

Table 3: Prevalence of Staphylococcus aureus, Escherichia coli, Klebsiella and Enterococcus in different studies.

\begin{tabular}{|lccccc|}
\hline Study group & Year & Staphylococcus aureus & Escherichia coli & Klebsiella & Enterococcus \\
\hline Khamees $^{19}$ & 2012 & $21.8 \%$ & $14.2 \%$ & $13.6 \%$ & - \\
\hline Demba et a ${ }^{20}$ & 2005 & $20.5 \%$ & - & - & - \\
\hline Present study & 2014 & $15.5 \%$ & $10.0 \%$ & $7.5 \%$ & $1.5 \%$ \\
\hline
\end{tabular}

Thulkar et al also reported a much higher prevalence of mixed infection $(147 / 400,36.8 \%)$ as compared to the present study. ${ }^{11}$ However this is in contrast to Sivaranjini et al who reported a mixed infection of 5.5\% (22/400)6 and Zimba et al. who found mixed infections in $11 \%$ cases. $^{6,8}$ Bacterial vaginosis in $34 \%$ cases, Trichomonas vaginalis in $2 \%$ and mixed infections in $11 \%$ cases with. Amongst other infections observed, Bacterial vaginosis was in majority in $43(21.5 \%)$ cases followed by Vulvovaginal Candidiasis in $31(15.5 \%)$ cases and Trichomonas vaginalis infection was identified in 3 $(1.5 \%)$ cases. This correlates to the studies conducted by Vishwanath et al., Bhalla et al. Patel et al. and Dan et al. ${ }^{12-15}$

The similar trends in Indian studies may be attributed to a conservative Indian society, where premarital or extramarital sexual contact is an exception rather than the rule. Hence, Bacterial vaginosis and Candidiasis, whose spread by sexual transmission is doubtful, are more prevalent when compared to Trichomonas vaginalis. In their study, Vishwanath et al, observed that the most common infection among 319 women was Bacterial vaginosis $(26 \%)$. They also observed that $10 \%$ of the patients were diagnosed with Trichomonas vaginalis. ${ }^{12}$ Similarly, in a population based study from both rural and urban communities by Bhalla et al on women in reproductive age group, the most common infection was bacterial vaginosis $(32.8 \%)$, followed by Candidiasis (16.9\%); Trichomonas vaginalis was diagnosed in $2.8 \%$ cases. ${ }^{13}$ Patel et al reported a lower prevalence of these infections in his study, $26.3 \%$ cases (from a population of 2494 women) were infected by endogenous infections (Bacterial vaginosis 17.8\%; Candidiasis 8.5\%). ${ }^{16}$ Dan et al, in their study on symptomatic women of reproductive age recuited from a gynecologic clinic in Israel also reported Candidiasis as the most common infection, $35.5 \%$ of the total population was diagnosed as infected with Candidiasis, followed by Bacterial vaginosis in $23.5 \%$ of women and Trichomonas vaginalis in $8.1 \%$ women. ${ }^{15}$

This was in contrast to the study by Puri et al. In their study on 100 sexually active women presenting with vaginal discharge, they found a much higher prevalence of Bacterial vaginosis in $45 \%$ cases and Candidiasis in $31 \%$. The prevalence of Trichomonas vaginalis was reported to in $2 \%$, which is in concurrence with our present study. ${ }^{16}$

Fonck et al. conducted a study in Kenya, where Candidiasis was most prevalent at $50 \%$, followed by Trichomonas vaginalis $23 \%$ and Bacterial vaginosis $9 \%$. The higher percentage of Trichomonas vaginalis in this study was probably because the study population was recruited from major sexually transmitted infection (STI) referral clinics in Kenya and $54 \%$ of the total population (621) was pregnant. ${ }^{17}$ Zaki et al found Bacterial vaginosis in $39.1 \%$ of patients, Trichomonas vaginalis in $30 \%$ and Candidiasis in $1 \%$ of patients. ${ }^{18}$ In present study secondary bacterial infections were found to be present in $34 \%$ (68 patients) of the study population. Among these the most common organism was found to be Staphylococcus aureus seen in $15 \%$ (30 patients) followed by Escherichia coli in $10 \%$ (20 patients), Klebsiella in $7.5 \%$ (15 patients) and Enterococcus in $1.5 \%$ (3 patients). This correlates with Khamees patients with Escherichia coli and $13.6 \%$ patients with Klebsiella. ${ }^{19}$ Demba et al who found Staphylococcus aureus in $20.5 \%$ patients. ${ }^{20}$ The $\mathrm{pH}$ of vaginal secretions was recorded as $>4.5$ and $<4.5$.A large than 4.5, these included women with Bacterial vaginosis, Trichomonas vaginalis and mixed infection but women with Candidiasis had $\mathrm{pH}$ which was slightly near the normal value. These results are in agreement with Caillouette et al, who demonstrated that $\mathrm{pH}$ value in patients with 
anaerobic bacterial infection is higher than that obtained from patients with either normal flora or yeast infection. ${ }^{21}$

In the present study, Bacterial vaginosis was diagnosed in $35 \%$ cases (70 patients) and was the most prevalent infections of all. It was diagnosed using Amsel's Criteria where 3 of the 4 patients had homogeneous thin confirming the diagnosis. ${ }^{22} 41$ of the 70 patients had homogeneous thin discharged, 54 gave positive whiff test with $\mathrm{KOH}$ (Amine test), in 45 cases the presence of clue cells was identified during wet mount and all 70 cases had $\mathrm{pH}>4.5$ In the present study, abnormal vaginal discharge was most prevalent in the age group of 21-40 years. The higher prevalence of pathogen infection Sobel who reported that at least $55 \%$ of the subjects have had at least one healthcare provider diagnosed episode to vaginal by age of 25 years. ${ }^{23}$ Similarly Khan and Khan showed that vaginal infections were common at the age of 15-30years. ${ }^{7}$

In the present study, we observed that majority of the patients $(95.5 \%)$ belonged to lower socio- economic class with monthly income less than Rs. 5113. This could also be attributed to the location of MMIMSR which is located in rural area. This correlates to a similar study conducted by Ifthikar et al who found that $85.3 \%$ of the patients belong to class II or below. ${ }^{24}$ Their study also followed the BG Prasad scale of classification and reported that all $100 \%$ of infected population belong to the lower socio- economic class ( $<$ Rs 5113/month income). ${ }^{25}$

In the present study we also observed that majority of the study population was poorly educated, $67 \%$ were either illiterate or attended primary school. This also correlates with Thulkar et al who found that $20 \%$ of their study population was uneducated and $53 \%$ had attended primary education. ${ }^{26}$

\section{CONCLUSION}

our findings show that Bacterial vaginosis is the most common Single infection followed by Candidiasis and Trichomonas vaginalis. There were also cases of mixed infections that were diagnosed.

Funding: No funding sources Conflict of interest: None declared

Ethical approval: The study was approved by the Institutional Ethics Committee

\section{REFERENCES}

1. Sobel J. Vaginitis Vulvitis, Cervicitis and Cultaneous Vulval Lesion. In Cohen J, Powderly WG, Opal SM. Infectious Diseases, Spain: Elsevier Ltd.; 2004.p. 683-91.

2. Mitchell H. Vaginal discharge- causes, diagnosis and treatment. BMJ. 2004;328(7451):1302-5.
3. Kumar P, Malhotra N. Jeffcoate's Principles of Gynaecology. 7th ed.: Jaypee Brothers Medical Pulishers. (P) Ltd.2008.

4. Eckert L, Lentz G. Infections of the lower genital tract: vulva, vagina, cervix, tixic shock syndrome, HIV infections. In Katz V, Lentz G, lobo R, Gershenson D, Comprshensive Gynecology. 6th ed.: Elseveir; 2012.P.519-60.

5. Rekha S, Jyothi S. Comparison of visual, clinical and microbilogical diagnosis of symptomatic vaginal discharge in the reproductive age group. Int J Pharm Biomed Res. 2010;1(4):144-8.

6. Sivaranjini R, Jaisankar T, Thapa D, Kumari R, Chandrasekhar L, Malathi M, et al. Spectrum of vaginal discharge in a tertiary care setting. Tropical $\mathrm{M}$, et al. Spectrum of vaginal discharge in a teriary care setting. Tropical Parasitol. 2013;3(2):135-9.

7. Khan I, Khan U. A hospital-based study of frequency of aerobic pathogens in vaginal infections. Rmj. 2004;29(1):22-5.

8. Zimba T, Apalata T, Sturm W, Moodley P. Aetiology of sexually transmitted infections in Maputo, Mozambique. J Infect Dev Ctries. 2001; 5(1):40-7.

9. Sobel J. Desquamative inflammatory vaginitis: a new subgroup of purulent vaginitis responsible to $2 \%$ clindamycin therapy. Am J Obstet Gynecol.1994; 171(5):1215-20.

10. Sobel J, Subramanian C, Foxman B, Fairfax M, Gygax S. Mixed vaginitismore thancoinfection and with therapeutic implications. Curr Infect Dis Rep. 2013;15(2):104-8.

11. Thulkar J, Kriplani A, Agarwal N, Vishnubhatla S. Aetiology and risk factors of recurrent vaginitis and its association with various contraceptive method . Indian J Med Res. 2010;131(1):83-7.

12. Vishwanath S, Talwar V, Prasad R, Coyaji K, Elias C, Zoysa I. Syndromic management of vaginal discharge among women in a reproductive health clinic in India. Sex Transm Infect. 2000; 76(4):3036.

13. Bhalla P, Chawla R, Garg S, Singh MM, Raina U, Bhalla $R$, et al. Prevalence of bacterial vaginosis among women in Delhi, India. Indian J Med Res. 2007;125(2):167-72.

14. Patel V, Weiss H, Mabey D, Weat B, D'Souza S, Patil V, et al. The burden and determinants of reproductive tract infections in India: a population based study of women in Goa, India . Sex Transm Infect. 2006;82(3):243-9.

15. Dan M, Kaneti N, Levin D, Poch F,Samra Z. Vaginitis in a Gynecologic Practice in Israel: Causes and Risk Factors. ISR Med Assoc J, 2003;5(9):62932.

16. Puri K, Madan A, Bajaj K. Incidence of various causes of vaginal discharge among sexually active females in age group 20-40 years. Indian J Dermatol Venereol Leprol. 2003;69(2):122-5.

17. Fonck K, Kidula N, Jaoko W, Estambale B, Claeys $\mathrm{P}$, Ndinya- Achola $\mathrm{J}$, et al. Validity of the vaginal 
discharge algorithm among pregnant and nonpregnant women in Nairobi, Kenya. Sex Transm Infect. 2000;76(1):33-8.

18. Zaki M, Rafaat D, Emsthaty W, Azab M, Hossam G. Correlation of Trichomonas Vaginalis to Bacterial Vaginosis: a Laboratory based study. J Infect Dev Ctries. 2010;4(3):156-63.

19. Khamees S. Characterization of vaginal discharge among women complaining of genital tract infection. Int J of Pharm and Life Sci. 2012;3(10):1997-2002.

20. Demba E, Morison L, Loeff MS, Awasana AA, Gooding E, Bailey R, et al. Bacterial vaginosis, vaginal flora patterns and vaginal hygiene practices in parients presenting with vaginal discharge syndrome in The Gambia, West Africa. BMC Infect Dis. 2005;5(1):12.

21. Caillouette J, Sharp CJ, Zimmerman G, Roy S. Vaginal $\mathrm{pH}$ as a marker for bacterial pathogens and menopausal status. Am J Obstet Gynecol. 1997; 176(6):1270-7.

22. Amsel R, Totten P, Spiegel C, Chen K, Eschenbach $\mathrm{D}$, Holmes K. Nonspecific vaginitis. Am J Med. 1983; 74(1):14-22.
23. Sobel J. Vulvovaginal candidosis. Lancet. 2007; 369(9577):1961-71

24. Ifthikar M, Dalmeida J, S S, Rao S, K R, Bangera $K$. Prevalence of bacterial vaginosis in pregnant women attending tertiary care setting. International J Recent Trends Sci Tech 2014;11(3):368-371.

25. Prasad B. Social classification of Indian families. J Indian Med Assoc. 1961;37:250-1.

26. Thulkar J, Kriplani A, Agarwal N, Vishnubhatla S. Aetiology and risk factors of recurrent vaginitis and its association with various contraceptive method. Indian J Med Res. 2010;131(1):83-7.

Cite this article as: Sood N, Sud SS. Profile of infection in women with vaginal discharge in North India. Int J Reprod Contracept Obstet Gynecol 2018;7:4184-9. 